\title{
Fibrinous Pericarditis and its Surgical Management in Cattle
}

\author{
D.R. Manjunatha, R.V. Suresh Kumar, B.N. Nagaraja, P. Veena, \\ P. Jagapathiramayya, Ch. Srilatha
}

10.18805/IJAR.B-4761

\begin{abstract}
Background: Traumatic pericarditis is one of the major problems encountered in cattle resulting in greater economic loss to the farming community and causes mortality. Diagnosis of heart diseases in animals is a challenging job for Veterinarians, bovines ingest foreign bodies (nails, thorns, glass pieces, metal wires, etc.) along with the feed and fodder which intern entangled in reticulum leading to traumatic pericarditis. The affected cattle shows drop in milk yield, sometimes death of affected animals especially pregnant or milking. The main aim of present study enlightens on diagnosis and surgical management of fibrinous pericarditis.

Methods: The clinical cases presented to Veterinary College Hospital, Hassan, suspected for pericarditis were selected for the present study, these animals were subjected for clinical, haemato-biochemical, ECG, radiological and ultrasonographic examination. In the total of 38 animals, six cattle were diagnosed as fibrinous_pericarditis_were subjected for pericardiotomy. Post operatively parenteral antibiotic and supportive therapy was given for 5-7 days.

Result: $5^{\text {th }}$ rib resection followed by pericardiotomy gave favourable result in animals suffering with fibrinous pericarditis. So early detection timely employment of suitable surgical technique can prolong the life of animal and can save the life of the young one.
\end{abstract}

Key words: Brisket, Fibrinous pericarditis, Pericardiotomy, Submandibular edema.

\section{INTRODUCTION}

Pericarditis is an inflammation of the pericardium with an accumulation of serous or fibrinous exudates. It is often attributable to reticular foreign bodies which penetrate the reticular wall, diaphragm and pericardial sac Radostits et al. (2007). Pathognomonic clinical signs are tachycardia, muffled heart sounds, asynchronous heart sounds such as rubbing or splashing sounds, jugular vein distension and brisket edema Braun et al. (2007).

The diagnosis of pericarditis in cattle is generally based on signs, clinical examination, pericardiocentesis, ultrasonography and thoracic radiography Imran et al. (2011). However, ultrasonography is still the method of choice for detecting characteristics of reticular motility, fibrinous deposits and abscessation which cannot be determined using radiography. Based on ultrasonographic finding pericarditis can be classified into serous pericarditis, suppurative pericarditis, fibrinous pericarditis and constrictive pericarditis Manjunatha et al. (2018). In the majority of cases, massive fibrinopurulent adhesions obscure the cardiophrenic angle, cardiac silhouette and ventral diaphragmEchogenic deposits and strands of fibrin are seen on the epicardium and the ventricles are compressed by the effusion Abdelaal et al. (2009). The present paper empahsises on clinico diagnostic studies and its management of fibrinous pericarditis in cattle.

\section{MATERIALS AND METHODS}

The study was conducted in the Department of Veterinary Clinical Complex, Veterinary College, Hassan during the year 2018-2020. Animals from Hassan region and its surrounding areas were selected for the study. A total of thirty eight cattle
Department of Veterinary Clinical Complex, Veterinary College, Karnataka Veterinary, Animal and Fisheries Sciences University, Hassan-573 202, Bidar, Karnataka, India.

Corresponding Author: D.R. Manjunatha, Department of Veterinary Clinical Complex, Veterinary College, Karnataka Veterinary, Animal and Fisheries Sciences University, Hassan-573 202, Bidar, Karnataka, India. Email: manjuvet328@gmail.com

How to cite this article: Manjunatha, D.R., SureshKumar, R.V., Nagaraja, B.N., Veena, P., Jagapathiramayya, P. and Srilatha, C. (2022). Fibrinous Pericarditis and its Surgical Management in Cattle. Indian Journal of Animal Research. DOI: 10.18805/IJAR.B-4761.

Submitted: 25-08-2021 Accepted: 13-12-2021

Online: 04-03-2022

brought to Teaching Veterinary Clinical Complex (TVCC), Hassan with the history of anorexia, brisket /jowl /ventral edema and pyrexia, jugular pulsation and cording were included in the study (Fig 1). Six cases of fibrinous pericarditis were selected and treated by $5^{\text {th }}$ rib resection followed by pericardiotomyand outcome of the study was described.

\section{Haematology and biochemistry}

Five milliliters of venous blood was collected in vacutainer tubes containing ethylene diamine tetra acetate (EDTA K3) as anticoagulant for haematological investigation and clot activator biochemical investigation. The parameters including packed cell volume (PCV), haemoglobin $(\mathrm{Hb})$, red blood cell (RBC), white blood cell (WBC) and differential counts (DC) were analyzed as per the manufacturer's instructions using Automated hematology analyser, ERMA Inc. Pvt. Ltd. (Jain, 1986). The biochemical parameters includes ALT (IU/dL), AST (IU/dL), Glucose (mg/dL), Plasma fibrinogen (g/dl), Total protein $(\mathrm{g} / \mathrm{dl})$, Albumin $(\mathrm{g} / \mathrm{dl})$, Globulin 
(g/dl), Sodium (mEq/mL), Potassium $(\mathrm{mEq} / \mathrm{mL})$ and Chloride $(\mathrm{mEq} / \mathrm{mL})$ were analyzed as per the manufacturer's instructions using semi automated biochemical analyser, SWEMED Inc, Pvt. Ltd. (Jain, 1986). Reference normal values were obtained from Radostits et al. (2007).

Based on inclusion and exclusion criteria, clinical signs, ECG, radiography and ultrasonography six animals of fibrinous pericarditis were selected for the study. Among six animals, five animals were female and one male belonging to different breeds like Amritmahal (01), HF cross breed (03) and Jersey cross breed (02) cattle's (Table 1). These animals had the history of fever, decreased milk yield, dullness, exercise intolerance, coughing, anorexia, recurrent bloat, submandibular and brisket edema.

All thecases suspected to havepericarditis were subjected for basic electrocardiographic examination to assess the status of cardiac function employing base- apex lead system. Using ECG machine (BPL medical Cardiart 3 channel ECG machine). The right arm lead was placed on the neck, the left arm lead on the chest wall just above the sternum and the neutral lead on the withers. The changes were only recorded when the heart rate was in the resting range and when the cows were standing on a rubber mat with paper speed of $25 \mathrm{~mm}$ per sec and amplitude of one $\mathrm{cm}$ equal to one $\mathrm{mV}$, was recorded as per the procedure described by Tharwat (2011).

Left latero lateral radiography of the caudoventral thorax and reticulum in standing position was performed in all the cattle as described by Braun (2009) using Allengers X-ray machine. The radiographic exposure factors of 90-100 kVp, 40-60 mAs and source image distance of $90 \mathrm{~cm}$ were employed. Computerized radiographic processes were made by using AGFA computerized radiographic unit. The radiographs were described based on presence or absence of radiopaque foreign body.

All the animals were restrained in standing position in a crate and thoracoabdominal region was shaved, washed, cleaned and transmission gel was applied liberally for optimal transmission of sound waves. Heartwas examined by scanning both sides of the costal part between four and fifth intercostals space by 3-5 MHz curvilinear ultrasonic transducer as per Braun et al. (2001). Ultrasound guided pericardiocentesis was performed and pericardial fluid was subjected for culturing and antibiotic sensitivity testing.
Based on clinical, electrocardiographic, radiological and ultrasonographic study confirmed cases of fibrinous pericarditis were subjected for $5^{\text {th }}$ rib resection followed by pericardiotomy. The skin incision wasmade from the costochondral junction to a point $25 \mathrm{~cm}$ dorsally on a line over the $5^{\text {th }}$ rib (Fig 2), the latissimusdorsi and serratus venteralis muscle were incised to expose the rib. Then the periosteum over the rib was incised and it was elevated with curved periosteal elevator to expose the rib. The rib was transacted by using Gigli wire saw at the proximal aspect of the incision (Fig 3) and disarticulated at the costochondral junction (Fig 4) and the portion of the rib was discarded (Anteneh and Ramswamy, 2015). The incision was then continued through the exposed periosteum and parietal pleura and after isolation of pericardium. The pericardium was incised and pericardial fluid was drained out using suction apparatus (Fig 5), then pericardial incision was extended to pass the hand into the pericardium to search foreign bodies and to break of adhesions between pericardium and epicardium. The pericardial sac was flushed with two litreswarm normal saline and metronidazole solutions. The Foleys catheter no $18 \mathrm{G}$ was placed into pericardial space. The pericardial incision was closed with simple continuous suture using No. 2 polyglactin 910 (Vicryl $^{R}$ Johnson and Johnson Intl). Parietal pleura, periosteum and intercostal muscles were re-apposed employing ford interlocking suture using No. 2 chromic catgut (TRUGUT ${ }^{\mathrm{R}}$ manufactured by Suture India Pvt. Ltd). Skin incision was closed with cross mattress suture using monofilament polyamide size 1 (TRULON $^{R}$ Suture India Pvt. Ltd) and foleys catheter was fixed to skin (Fig 6) (Dehghani and Molaei, 1999, Gavali et al. (2003). Postoperativelypericardial cavity was flushed with 2 litres of warm normal saline followed by $200 \mathrm{ml}$ of metronidazoleonce daily for five days through foleys catheter. The bovines which had radiographic foreign body in the reticulum, rumenotomy was performed under left paravertebral nerve block Tranquilli et al. (2007) and foreign bodies were retrieved (Fig 7) employing standard surgical procedure.

Post operatively parenteral antibiotics were selected based on ABST (Antibiotic sensitivity testing) report, supportive therapy like B-complex $10 \mathrm{ml}$ intra muscularly, diuretics like frusemide $2 \mathrm{mg} / \mathrm{kg}$ body weight intra muscularly and fluid therapy is infused at the rate of $20 \mathrm{ml}$ per $\mathrm{kg}$ body weight per day was given for three days (Fig 8).

Table 1: Signalment and anamnesis of fibrinous pericarditis in six cattle under study.

\begin{tabular}{|c|c|c|c|c|c|c|c|c|}
\hline $\begin{array}{l}\text { Case } \\
\text { no. }\end{array}$ & Breed & Age & Gender & $\begin{array}{l}\text { Physiological } \\
\text { status }\end{array}$ & $\begin{array}{l}\text { Brisket } \\
\text { edema }\end{array}$ & $\begin{array}{l}\text { Submandi } \\
\text { bular } \\
\text { edema }\end{array}$ & $\begin{array}{l}\text { Abduction } \\
\text { of elbow }\end{array}$ & $\begin{array}{l}\text { Jugular } \\
\text { pulsation }\end{array}$ \\
\hline 1 & Holstein friesian cross breed & 4 years & Female & Non pregnant & +++ & +++ & +++ & ++ \\
\hline 2 & Holstein friesian cross breed & 4.6 years & Female & 15 days after calving & +++ & +++ & +++ & +++ \\
\hline 3 & Holstein friesian cross breed & 6.6 years & Female & Eight months pregnant & ++ & + & ++ & ++ \\
\hline 4 & Amruthmahal & 3.5 years & Male & NA & ++ & + & + & + \\
\hline 5 & Jersey cross breed & 4 years & Female & Seven months pregnant & +++ & ++ & ++ & ++ \\
\hline 6 & Jersey cross breed & 3.6 years & Female & one month after calving & +++ & ++ & +++ & +++ \\
\hline
\end{tabular}




\section{RESULTS AND DISCUSSION}

Clinical examination of cattle affected with fibrinouspericarditis revealed brisket and submandibular edema, bilateral jugular pulsation, cording of jugular vein, reluctant to move downwards, arched back, abducted elbow, tachycardia and muffled heart sound were pathognomonic sign in diagnosing fibrinous form of pericarditis. Similar observations were made by Imran et al. (2011), Tharwat (2011) Ashwani Kumar et al. (2012) and Anteneh and Ramaswamy (2015).

The haematological evaluation of these cases revealed decreased hemoglobin and moderately increased total leukocyte count with shift to left. The biochemical values like protein albumin and plasma fibrinogen were slightly elevated than normal (Table 2). Decreased hemoglobin and moderately increased total leukocyte count with shift to leftmight be due to toxaemic condition of the body Manjunatha et al. (2018). Increased values of protein albumin and plasma fibrinogenin in the present this study was in accordance with the Athar et al. (2012), Hussein and Staufenbiel (2014) and Manjunatha et al. (2018). Statistical analyses of collected data were analyzed by one-way ANOVA, using computer based SPSS statistics software 15.0 version following Duncan's Post Hoc.

Electrocardiography showed non-significant increase in the heart rate, increased P-R interval and decreased QRS

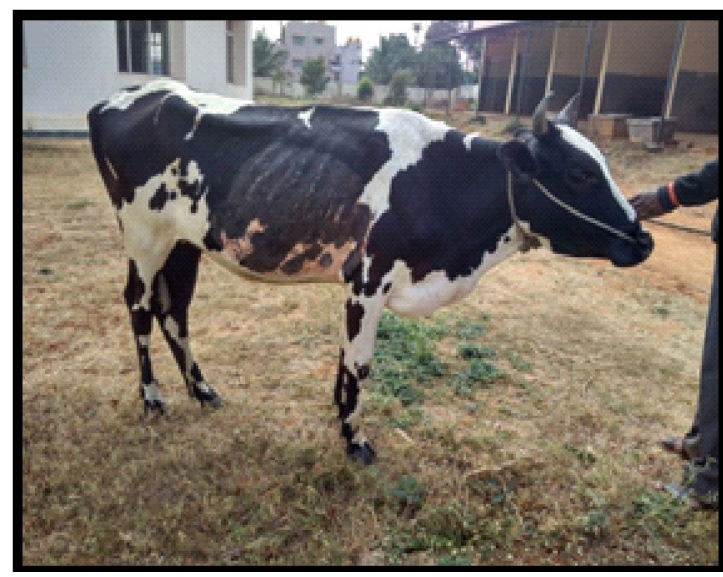

Fig 1: Cattle with submandibular and brisket edema.

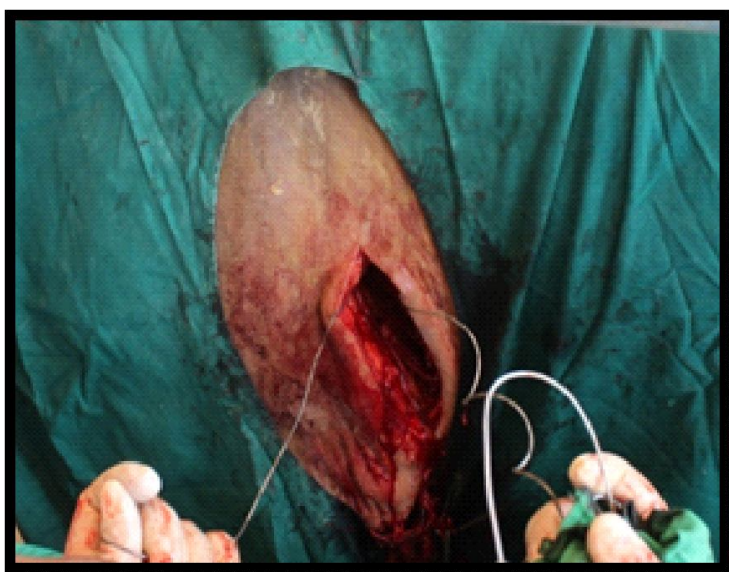

Fig 3: Transaction of rib by gigli wire saw. complex. These observations were in accordance with Tharwat (2011) and Athar et al. (2012).

Radiological examination aimed at localizing the foreign bodies. Out of six animals two animals did not reveal radioopaque foreign body and four animals showed presence of radioopaque foreign body in the reticulum (Fig 9). The radiography was helpful in finding of radiopaque foreign body in reticulum or thorax. Radiological characteristic of pericarditis affected animals is in correlation with the Sasikala et al. (2018) and Premkumar et al. (2019).

Cardiac ultrasonography was performed in a larger area extended from $3^{\text {rd }}$ to $5^{\text {th }}$ intercostal space on both left and right side.Ultrasonographyrevealed hypoechoicareas with echogenic deposits suggestive of strands of fibrin interspersed in between the pericardial sac and in some cases strands of fibrin were seen floating in the fluid between the epicardium and pericardium. Thick echogenic pericardial membrane was surrounding the heart with echogenic bands between them. The heart chambers were moderately compressed and pericardial depth varied from 2.3 to 6.2 $\mathrm{cm}$ (Fig 10 and Table 3). These findings were in accordance with earlier authors (Buczinski 2010, Imran et al. (2011), Tharwat (2011), Ashwani Kumar et al. (2012) Athar et al. (2012), Attia (2016), Ibrahim and Gomaa (2016), Khalphallah et al. (2017), Sasikala et al. (2018) and Premkumar et al. (2019).

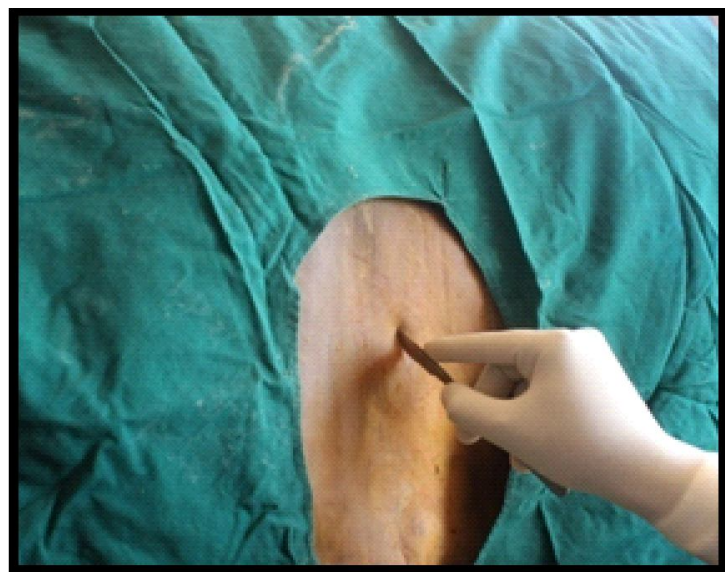

Fig 2: Skin incision for thoracotomy and pericardiotomy.

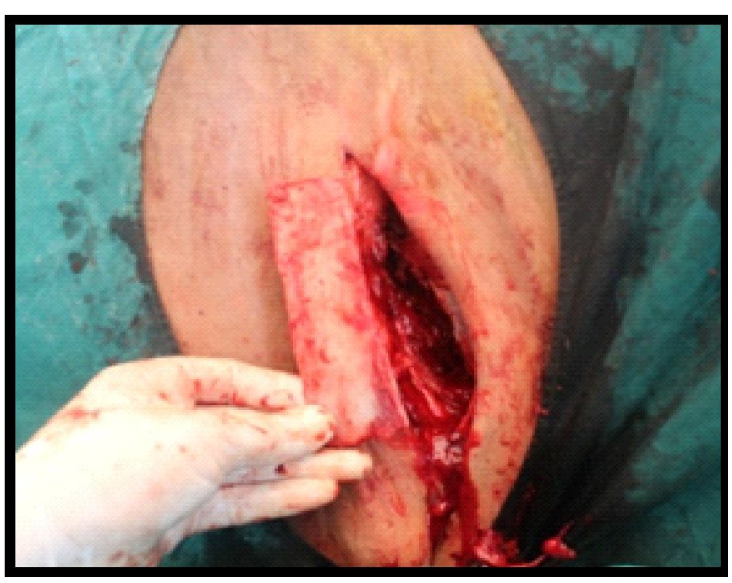

Fig 4: Complete removal of rib. 
Ultrasound guided pericardiocentesis helped to confirm the nature of the pericardial fluid. The fluid colour was brownish with foul smelling (2 cases), reddish brown with bad smell ( 2 cases), straw color fluid without smell and yellow color with bad odourinone case each. Athar et al. (2012)

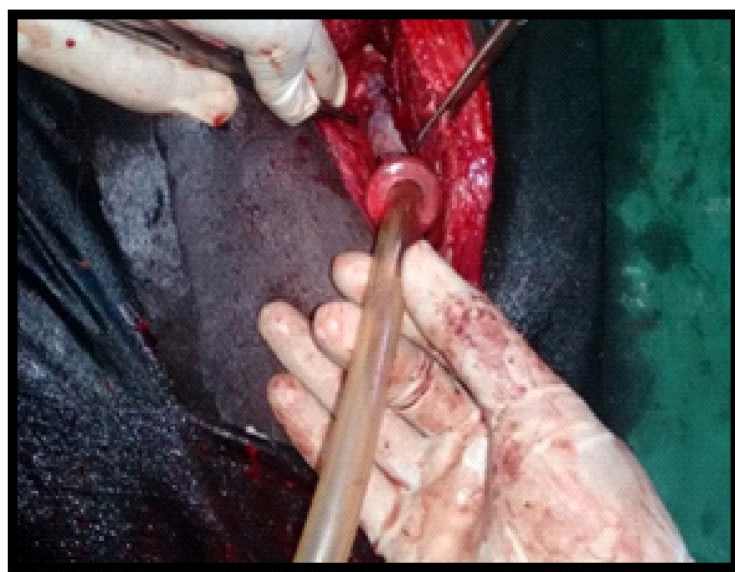

Fig 5: Draining of pericardial fluid from pericardial sac by suction pump.

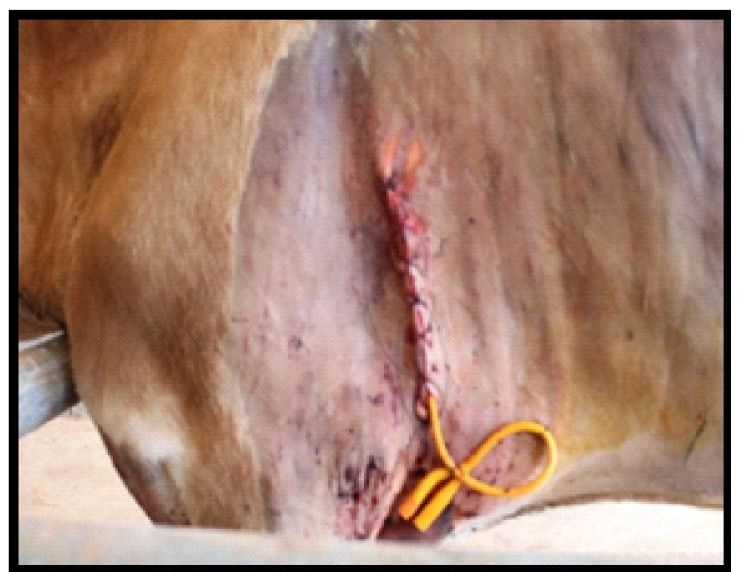

Fig 6: Closure of skin incision and fixing of Foleys catheter to skin.

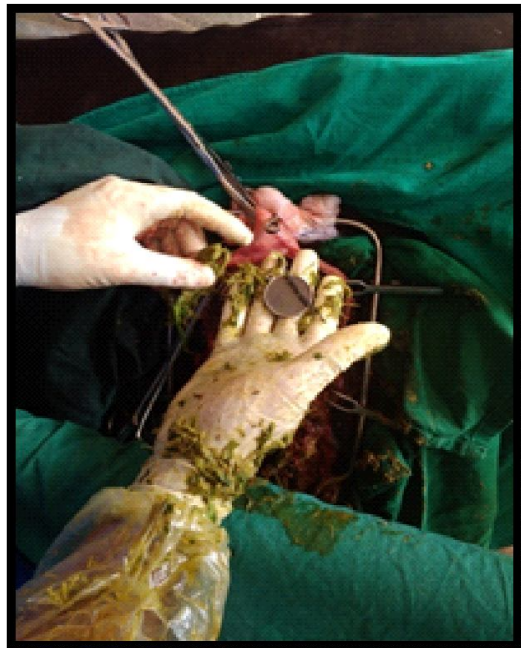

Fig 7: Foreign body removal through rumenotomy. reported that pericardial fluid colour and smell vary according to the etiological agent involved and Misk (2015) opined that the pericardial fluid aspirates were yellowish, reddish, or whitish in colour with different viscosity according to the severity of the disease.

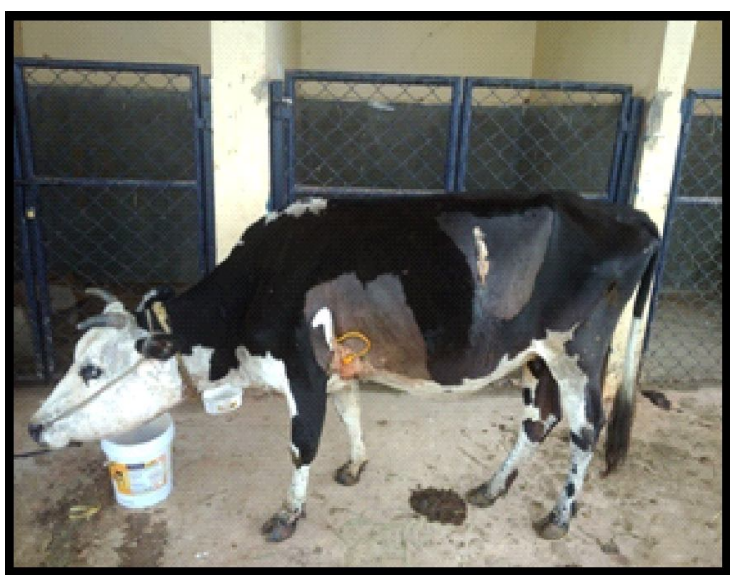

Fig 8: Post operative photographs.

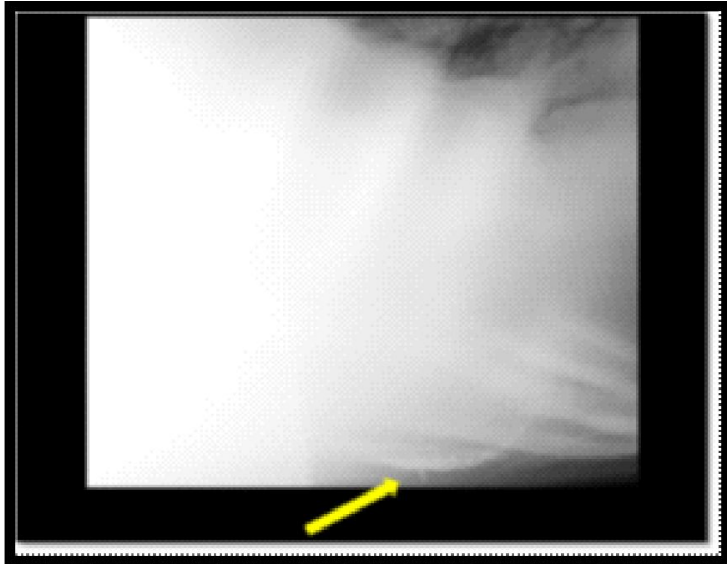

Fig 9: Lateral thoracic radiograph showing radioopaque sharp foreign body piercing the reticular wall.

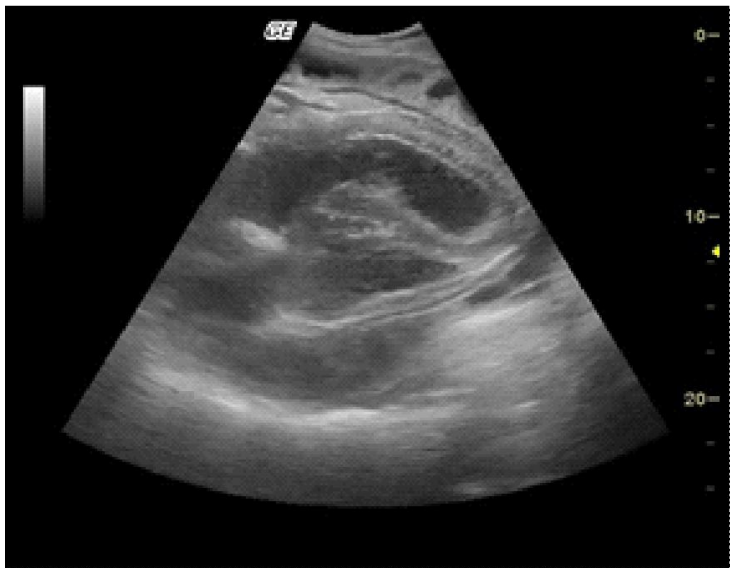

Fig 10: Ultrasound image showing hypoechoic areas with echogenic deposits suggestive of strands of fibrin interspersed in between the pericardial sac. 
Bacteriological isolation and culturing of pericardial fluid revealed presence of E. coli in two cases, Staphylococcal, Clostridia, Pasteurellaand mixed infection in one case each.

Table 2: Mean \pm SE Haemato biochemical values of cattle affected with fibrinouspericarditis.

\begin{tabular}{|c|c|c|}
\hline Parameters & Values & Reference value \\
\hline $\mathrm{Hb} \mathrm{g} \%$ & $7.783 \pm 0.480$ & $8-15$ \\
\hline PCV \% & $24.5 \pm 1.574$ & $24-46$ \\
\hline TEC (millions/ $\mu \mathrm{L}$ ) & $5.35 \pm 0.239$ & $5-10$ \\
\hline Leukocyte count $/ \mu \mathrm{L}$ & $11 \pm 0.53$ & $5-12$ \\
\hline Lymphocytes (\%) & $57.5 \pm 1.335$ & $45-75$ \\
\hline Neutrophils (\%) & $44 \pm 1.335$ & $15-45$ \\
\hline Monocytes (\%) & $4.5 \pm 0.224$ & $2-7$ \\
\hline Eosonophils (\%) & $1.5 \pm 0.224$ & $2-20$ \\
\hline platelets (lakhs $/ \mu \mathrm{L}$ ) & $3.12 \pm 0.294$ & $2-8$ \\
\hline ALT (IU/dL) & $55.33 \pm 0.955$ & $45-70$ \\
\hline AST (IU/dL) & $76 \pm 1.612$ & $45-80$ \\
\hline Glucose $(\mathrm{mg} / \mathrm{dl})$ & $92.17 \pm 3.016$ & $62-114$ \\
\hline Plasma fibrinogen ( $g / d l)$ & $0.94 \pm 0.036$ & $0.3-0.7$ \\
\hline Total protein (g/dl) & $7.78 \pm 0.135$ & $6.7-7.5$ \\
\hline Albumin (g/dl) & $4.0 \pm 0.112$ & $2.1-3.6$ \\
\hline Globulin (g/dl) & $3.78 \pm 0.13$ & $2.0-3.9$ \\
\hline $\mathrm{A} / \mathrm{G}$ ratio & $1.05 \pm 0.15$ & $1.1-2.4$ \\
\hline Sodium (mEq/mL) & $134.21 \pm 0.23$ & $130-140$ \\
\hline Potassium (mEq/mL) & $3.62 \pm 0.32$ & $3.9-5.0$ \\
\hline Chloride $(\mathrm{mEq} / \mathrm{mL})$ & $103.13 \pm 0.53$ & $95-110$ \\
\hline
\end{tabular}

Antibiogram in present study suggested that the organisms were sensitive for Ciprofloxacin, Gentamicin, Penicillin, Amoxicillin, Streptomycin and Ceftriaxone (Table 4). Cytological examination of the pericardial fluid revealed presence of bacteria and degenerated neutrophils suggestive of infection and inflammation. Whereas Imran et al. (2011) reported gram negative bacilli in pericardial fluid, Manjunatha et al. (2018) reported presence of E-coli, Staphylococcal and bacteriological sterile cases in pericardial fluid of cattle. A mixed population of Gram's positive and Gram's negative aerobic and anaerobic organisms (gastrointestinal flora) sensitive to cephalexin, gentamicin, cotrimethoxazole, tetracycline and erythromycin as reported by Athar et al. (2012).

In the present study, pericardiotomy by $5^{\text {th }}$ rib resection under local analgesia in standing position was performed as per procedure of Hendrickson (2007) which was found to be effective. Upon pericardiotomy $200 \mathrm{ml}$ to $2000 \mathrm{ml}$ of fluid was removed, hand was passed into pericardium for breaking of adhesions and examined for foreign bodies and Foleys catheter no-18 was placed in the pericardial cavity and fixed to skin. The foreign bodies like sewing needle and wire were removed from the reticulum by rumenotomy underleft $T_{13}, L_{1}$ and $L_{2}$ paravertebral nerve block.

Postoperatively parental antibiotics were administered as per ABST reports likeceftriaxone sodium in three cases penicillin in two cases and amoxicillin in one case for seven days.Analgesic meloxicam was administered for three days. Supportive therapy like fluids, diuretics, B-complex supplements and anti-histamines was given for 5-7 days.

Table 3: Ultrasonographic features in Fibrinous pericarditis.

\begin{tabular}{|c|c|c|c|}
\hline $\begin{array}{l}\text { Case } \\
\text { no. }\end{array}$ & Breed & Ultrasonographic finding & $\begin{array}{l}\text { Depth of } \\
\text { pericardial space }\end{array}$ \\
\hline 1 & Holstein friesian cross breed & $\begin{array}{l}\text { Hyperechoicfibrinous strands attachment between } \\
\text { epicardium and pericardium with anechoic fluid in } \\
\text { between strand of fibrin }\end{array}$ & $3.2 \mathrm{~cm}$ \\
\hline 2 & Holstein Friesian cross breed & $\begin{array}{l}\text { Hyperechoicfibrinous strands floating in the mixture } \\
\text { of hyperechoic to echoic fluid in the pericardial space }\end{array}$ & $3.1 \mathrm{~cm}$ \\
\hline 3 & Holstein Friesian cross breed & $\begin{array}{l}\text { Hypoechoic contents with hyperehoic strands floating } \\
\text { in pericardial space }\end{array}$ & $2.6 \mathrm{~cm}$ \\
\hline 4 & Amruthmahal & $\begin{array}{l}\text { Anechoic to echoic to fluid accumulation in the pericardial } \\
\text { with hyper echoic fibrinous strands attached to heart }\end{array}$ & $2.3 \mathrm{~cm}$ \\
\hline 5 & Jersey cross breed & $\begin{array}{l}\text { Mild anechoic fluids containshyperecoic fibrin } \\
\text { attachment to pericardial sac }\end{array}$ & $4.1 \mathrm{~cm}$ \\
\hline 6 & Jersey cross breed & $\begin{array}{l}\text { Massive echoic fluids containing few streaks of } \\
\text { hyperechoic fibrin strands floating in pericardial fluid }\end{array}$ & $6.2 \mathrm{~cm}$ \\
\hline
\end{tabular}

Table 4: Pericardial fluid analysis and antibiogram.

\begin{tabular}{lllll}
\hline Case no. & Breed & Color of pericardial fluids & Organism & Antibiotic sensitivity \\
\hline 1 & Holstein friesian cross breed & Reddish to brown & Mixed infection & Ceftriaxone \\
2 & Holstein friesian cross breed & Yellowish & Pasturella & Penicillin \\
3 & Holstein friesian cross breed & Brownish & Clostridia & Ceftriaxone \\
4 & Amruthmahal & Reddish brown & Ecoli & Ceftriaxone \\
5 & Jersey cross breed & Brownish & Ecoli & Amoxicillin \\
6 & Jersey cross breed & Straw & Staphylococcal & Penicillin \\
\hline
\end{tabular}


In total of six animals, one animal died on firstsurgical day, one died on fifth postoperative day, another two pregnant animals survived for 2 months and born to calf and alternative two animals survived for 6 months.

Proper placement of catheter in this study helped in proper drainage of pericardial or pleural accumulation in effective way. Braun (2009) opined that cattle almost have a poor prognosis and should be humanely euthanized as quick as possible and treatment should be attempted only in a valuable animal or in animal carrying high value embryo, whereas, in present study $5^{\text {th }}$ rib resection followed by pericardiotomy yielded favorable result in animals suffering with fibrinous pericarditis. So early detection timely employment of suitable surgical technique can prolong the life of animal and can save the life of the young one.

\section{CONCLUSION}

Pericardiotomyis a reliable good technique in management of fibrinouspericarditis, this technique was helpful in breaking adhesions between epicardium and pericardium.

\section{ACKNOWLEDGEMENT}

Authors are thankful to the Honourable Vice Chancellor and Registrar of KVAFSU, Bidar and SVVU, Tirupathi for providing necessary facilities to complete present research study.

\section{Conflict of Interest: None.}

\section{REFERENCES}

Abdelaal, A.M., Floeck, M., Maghawry, S.E. and Baumgartner, W. (2009). Clinical and ultrasonographic differences between cattle and buffaloes with various sequelae of traumatic reticuloperitonitis. Veterinari Medicina. 54: 399-406.

Anteneh, M. and Ramaswamy, V. (2015). Hard ware disease in bovine (review article), Academic Journal of Animal Diseases. 3: 146-159.

Ashwani Kumar, Narinder S. Saini, Jitender Mohindroo and Naresh K. Sood. (2012). Ultrasonographic features of normal heart and liver in relation to diagnose pericarditis in bovine. Indian Journal of Animal Sciences. 12: 1489-1494.

Athar, H., Parrah, J.D., Moulvi, B.A., Singh M. and Dedmari, F.H. (2012). Pericarditis in Bovines- A Review. International Journal of Advanced Veterinary Science and Technology. 1: 19-27.

Attia, N.E. (2016). Cardiac biomarkers and ultrasonography as tools in prediction anddiagnosis of traumatic pericarditis in Egyptian buffaloes. Veterinary World. 9(9): 976-982.

Braun, U. (2009). Traumatic pericarditis in cattle: Clinical, radiographic and ultrasonographic findings. Veterinary Journal. 182: 176-186.

Braun, U., Schweizer, T. and Pusterla, N. (2001). Echocardiography of the normal bovine heart: Technique and ultrasonographic appearance. Veterinary Record. 148: 47-51.

Braun, U., Lejeune, B., Schweizer, G., Puorger, M. and Ehrensperger, F. (2007). Clinical findings in 28 cattle with traumatic Pericarditis. Veterinary Record. 161: 558-563.
Buczinski, S., Francoz, D., Fecteau, G. and Di Frusica, R. (2010). Heart diseases in cattle with clinical signs of heart failure: 59 cattle. Canadian Veterinary Journal. 51: 1123-1129.

Dehghani, S.N. and Molaei, M.M. (1999). Pericardiotomy Vs intermittent pericardial lavage for treatment of pericarditis in cattle: An experimental study. Indian Journal of Veterinary Surgery. 20: 22-24.

Gavali, M.B., Aher, V.D. and Bhikane, A.U. (2003). Surgical management of traumatic pericarditis in bovine - A clinical study. Indian Veterinary Journal. 80: 556-559.

Hendrickson, D.A. (2007). Rib Resection and Pericardiotomy. In: Techniques of Large Animal Surgery. ( $3^{\text {rd }}$ Edn.) Lea and Febiger, USA. 282-286.

Hussein, H.A. and Staufenbiel, R. (2014). Clinical presentation and ultrasonographic findings in buffaloes with congestive heart failure. Turkish Journal of Veterinary and Animal Science. 38: 534-545.

Ibrahim, H.M.M. and Gomaa, N.A. (2016). Traumatic pericarditis in cattle: Risk factors clinical features and ultrasonographic findings. Journal of Veterinary Science and Medical Diagnosis. 3: 1-6.

Imran, S., Tyagi, S.P. and Sharma, S. (2011). Ultrasonographic application in the diagnosis and prognosis of pericarditis in cows. Veterinary Medicine International. 10: 1-10.

Jain, N.S., (1986). Haematological Techniques. In: Schalm's Veterinary Haematology. $4^{\text {th }}$ edn., Lea and Febiger, Philadelphia. pp. 20-86.

Khalphallah, A., Hanan, K., Abedellaah Doaa, Salman Al-lethie, A. Al-lethieand Sara Bayoumi, A. (2017). Ultrasonography as a diagnostic tool in Egyptian buffaloes with traumatic pericarditis. International Journal of Veterinary Science and Medicine. 2: 159-167.

Manjunatha, D.R., Nagaraju, N., Basavarju, B.B., Suresh, L., Dilipkumar, D., Shivaprakash, B.V. and Vasanth, M.S. (2018). Traumatic pericarditis in bovines: Its diagnosis and surgical management; Journal of Veterinary Surgery. 2: 96-99.

Misk, N.A. (2015). Thoracocentesis for diagnosis of traumatic pericarditis and diaphragmatic hernia in cattle and buffaloes. Assiut Veterinary Medicine Journal. 145: 70-74.

Premkumar, C., Dharmaceelan, S., Rajendran, N. and Jagadeeswaran, A. (2019). Ultrasound diagnosis and pericardiocentesis under local analgesia for traumatic pericarditis in cattle A clinical study. The Pharma Innovation Journal. 3: 92-96.

Radostits, O.M., Gray, C.C., Hinchcliff, K.W. and Constable, P.D. (2007). Veterinary Medicine A Textbook of the Diseases of Cattle, Horses, Sheep, Pigs and Goats. (10 $0^{\text {th }}$ Edn.). Saunders Elsevier, Philadelphia. pp. 430-32.

Sasikala, K., Vijayakumar, G., Sivaraman, S. and Balasubramaniam, G.A. (2018). Clinicodiagnostic studies on traumatic reticulopericarditis in cattle - A review of 56 cases. International Journal of Current Microbiology and Applied Sciences. 5: 513-523.

Tharwat, (2011). Traumatic Pericarditis in Cattle: Sonographic, Echocardiographic and Pathologic Findings. Journal of Agricultural and Veterinary Sciences Qassim University. 1: 45-59.

Tranquilli, W.J., Thurmon, J.C. and Grimm, K.A. (2007). Lumb and Jones' Veterinary Anesthesia and Analgesia. ( $4^{\text {th }}$ edn.). Blackwell Publishers, pp. 731-743. 